\section{Intoxication and Deaths Associated with Ingestion of a Racing Fuel and Carbonated Soft Drink Mixture - Tennessee, January 2016}

Mary-Margaret A. Fill, MD ${ }^{1,2}$; Donna L. Seger, MD 3 ; John R. Dunn, DVM, PhD ${ }^{2}$; William Schaffner, $\mathrm{MD}^{4}$; Timothy F. Jones, $\mathrm{MD}^{2}$

In January 2016, the Tennessee Poison Center and Tennessee Department of Health learned of the deaths of two adolescents, and the nonfatal intoxication of two other adolescents, after ingestion of a mixture of racing fuel (approximately $100 \%$ methanol) and a carbonated soft drink. The Tennessee Department of Health reviewed medical records and police reports to learn more about the racing fuel source, assess ongoing risk, and guide prevention efforts. These are the first reported deaths in the United States associated with ingestion of this racing fuel mixture.

Police investigators reported that one of the decedents obtained approximately one half gallon (1.9 L) of an unknown brand of racing fuel from a family friend's residence. Unknown quantities of racing fuel and the carbonated soft drink were subsequently mixed in a $2 \mathrm{~L}$ bottle, and consumed at a party, presumably as a substitute for ethyl alcohol. The two surviving adolescents reported drinking approximately 2 ounces $(59 \mathrm{~mL})$ of the mixture. The amount consumed by the two decedents is unknown, although an empty $2 \mathrm{~L}$ bottle was recovered at the scene. According to police reports, no other adolescents interviewed reported ingesting the mixture.

The first decedent, a male aged 16 years, was found dead at home approximately 11 hours after ingesting the mixture. The second decedent, also a male aged 16 years, was observed having seizure-like activity at home approximately 12 hours after ingestion and was transported to a local emergency department. Initial laboratory tests were notable for severe metabolic acidosis and a blood methanol level of $175 \mathrm{mg} / \mathrm{dL}$ (the presence of any methanol is abnormal). He was treated with aggressive measures, including fomepizole, a competitive inhibitor of alcohol dehydrogenase, and hemodialysis; however, he died 5 days after ingestion. The two surviving adolescents were evaluated in emergency departments 20-23 hours after ingestion, reported to have normal laboratory evaluations, and released.

The life-threatening component of the consumed mixture, racing fuel, is approximately $100 \%$ methanol. Methanol is an organic solvent commonly found in laboratory, industrial, automotive, and residential products (1). Methanol is metabolized to formaldehyde and then to formic acid, which accumulates in the optic nerve and optic disc and is highly cytotoxic (2). As little as $15 \mathrm{ml}$ (0.5 ounce or 1 tablespoon) of methanol can be fatal (1).

The initial signs and symptoms of methanol intoxication are similar to those of ethanol intoxication. After a latent period of 6-36 hours, depending upon the amount ingested, patients develop drowsiness and gastrointestinal symptoms (nausea, vomiting, and abdominal pain), reflecting the metabolism of methanol, via formaldehyde, to formic acid. Concomitant consumption of ethanol can prolong the latent period (2). Later, more serious symptoms, including visual disturbances, abnormal respiration, altered mental status, seizures (related to metabolic derangement or brain injury), cerebral edema, and death, can occur (2-4). However, the absence of severe signs or symptoms after ingestion should not deter medical evaluation (1); early medical assessment and rapid treatment can increase chances for survival $(2,5)$.

The surviving adolescents had not heard of or consumed this racing fuel and carbonated soft drink mixture before; however, they reported that one of the decedents learned of the mixture on a trip to Kansas approximately 1 month earlier. State and national poison control and public health officials who were questioned were unaware of this practice. However, outbreaks of methanol poisoning caused by novice or illicit production of spirits have been previously documented in the United States and around the world, sometimes causing hundreds of deaths per outbreak (6-8). These dangerous beverages are produced as a cheap substitute for ethyl alcohol, often in areas where alcohol is banned or expensive. Methanol is a known byproduct of fermentation and is found at safe levels in most alcoholic beverages; however, if the distillation process is performed incorrectly, as can occur in home-brewed or illicit beverages, methanol levels can be dangerously elevated (8).

The American Association of Poison Control Centers' Toxic Exposure Surveillance System includes 7,183 reports of methanol exposure for the period 2011-2014; among these exposures, 660 (9.2\%) were intentional. Among all 7,183 persons exposed, 477 (6.6\%) patients who survived had symptoms of moderate or major toxicity, ${ }^{*}$ and $33(0.5 \%)$ died. However,

\footnotetext{
*From definitions used by the Toxic Exposure Surveillance System. Moderate toxicity: The patient exhibits some symptoms as a result of the exposure, but they are minimally bothersome. The symptoms usually resolve rapidly and often involve skin or mucous membrane manifestations. The patient returns to a preexposure state of well-being and has no residual disability or disfigurement (examples include mild gastrointestinal symptoms, drowsiness, and sinus tachycardia without hypotension). Major toxicity: The patient exhibits symptoms as a result of the exposure which are life-threatening or result in significant residual disability or disfigurement (examples include patients who require intubation and mechanical ventilation or have cardiovascular instability).
} 
a more accurate estimate of the methanol case-fatality rate considers the proportion of deaths among all persons who had moderate or major toxicity (33 of 510 [6.5\%]), because the persons in these groups were most likely to be at risk for death. With the exception of three patients (aged 13-19 years), all methanol exposure deaths occurred among persons aged $\geq 20$ years (9).

Parents, community educators and leaders, and the medical and public health communities are important in the monitoring of similar practices among adolescents, and in consistently reinforcing the message that methanol is a highly toxic substance that can cause serious illness and death. The Tennessee Department of Health has developed educational materials for use by community educators statewide, including a one-page brief fact sheet and didactic presentation. These educational materials include background information on the mixture of racing fuel and the carbonated soft drink, symptoms of methanol ingestion, recommendations to seek medical care as soon as possible, and 24/7 contact information for the Tennessee Poison Center and Tennessee Department of Health. Collaborative prevention efforts among the Tennessee Poison Center, the Tennessee Department of Health, and local communities are ongoing.

${ }^{1}$ Epidemic Intelligence Service, CDC; ${ }^{2}$ Tennessee Department of Health, Division of Communicable and Environmental Diseases and Emergency Preparedness, Nashville, Tennessee; ${ }^{3}$ Tennessee Poison Center, Nashville; ${ }^{4}$ Department of Health Policy, Vanderbilt University School of Medicine, Nashville.

Corresponding author: Mary-Margaret A. Fill, mfill@cdc.gov, 615-532-6752.

\section{References}

1. Kruse JA. Methanol and ethylene glycol intoxication. Crit Care Clin 2012;28:661-711. http://dx.doi.org/10.1016/j.ccc.2012.07.002

2. Barceloux DG, Bond GR, Krenzelok EP, Cooper H, Vale JA; American Academy of Clinical Toxicology Ad Hoc Committee on the Treatment Guidelines for Methanol Poisoning. American Academy of Clinical Toxicology practice guidelines on the treatment of methanol poisoning. J Toxicol Clin Toxicol 2002;40:415-46. http://dx.doi.org/10.1081/ CLT-120006745

3. Fontenot AP, Pelak VS. Development of neurologic symptoms in a 26-year-old woman following recovery from methanol intoxication. Chest 2002;122:1436-9. http://dx.doi.org/10.1378/chest.122.4.1436

4. Lu JJ, Kalimullah EA, Bryant SM. Unilateral blindness following acute methanol poisoning. J Med Toxicol 2010;6:459-60. http://dx.doi. org/10.1007/s13181-010-0024-7

5. Hovda KE, Hunderi OH, Tafjord AB, Dunlop O, Rudberg N, Jacobsen D. Methanol outbreak in Norway 2002-2004: epidemiology, clinical features and prognostic signs. J Intern Med 2005;258:181-90. http:// dx.doi.org/10.1111/j.1365-2796.2005.01521.x

6. Bennett IL Jr, Cary FH, Mitchell GL Jr, Cooper MN. Acute methyl alcohol poisoning: a review based on experiences in an outbreak of 323 cases. Medicine (Baltimore) 1953;32:431-63. http://dx.doi. org/10.1097/00005792-195312000-00002

7. Swartz RD, Millman RP, Billi JE, et al. Epidemic methanol poisoning: clinical and biochemical analysis of a recent episode. Medicine (Baltimore) 1981;60:373-82. http://dx.doi. org/10.1097/00005792-198109000-00005

8. World Health Organization. International Programme on Chemical Safety. Environmental health criteria no. 196: methanol. Geneva, Switzerland: World Health Organization; 1997.

9. American Association of Poison Control Centers. National Poison Data System: annual reports, 2011-2014. Alexandria, VA: American Association of Poison Control Centers. http://www.aapcc.org/ annual-reports/ 